\title{
Modeling and implementation of sequencing of tasks to maximize the processing in an organization
}

\author{
A. NAMIR, A. EL KEBBAJ, R. NAMIR and S.EZZBADY \\ Laboratory of Modeling and Information Technology, \\ Department of Mathematics and Computer Science, \\ Faculty of Sciences Ben M'sik, Hassan2-Mohammedia University, \\ B.P 7955, \Sidi Othman,Casablanca, Morocco \\ a.namir@yahoo.fr, amina.elkebaj@gmail.com,rnamir@gmail.com, \\ souadezzbady@gmail.com
}

\begin{abstract}
The main objective of this work is to conceive a practical approach to improve customer's satisfaction which is generally considered as the pillar of the development of customer fidelity for the company. It is necessary to have a platform which we master to manage to satisfy the customer by studying its needs, by having the capacity to be close and serving him for the shortest deadlines.

The waiting time before being served is systematically badly noted by the customers and can cause their dissatisfactions. For that, it is necessary to find a way to decrease the dissatisfaction of the customer by improving the service.

We propose in this work, a simple and practical approach for modeling and implementation of a sequencing of tasks to maximize the processing in an organization. This approach respects the constraints of the organization and eliminates any shape of wasting of time at the level of service. She can be personalized for any company, as long as an organizational structure including the actors is defined, the authorities as well as the skills required for every participant in the organization.

The problem is mathematically modeled by an integer linear programming and in series solved numerically by respecting rules of priority at the level of the departments. At the end, practical examples to illustrate the work are given.
\end{abstract}

\section{Keywords}

Communication network, Information system, Maximization, Modeling, Quality of Service (QoS), Satisfaction, Sequencing, Processing.

\section{Academic Discipline And Sub-Disciplines}

Mathematics and Computer Science

\section{SUBJECT CLASSIFICATION}

Business Intelligence

\section{TYPE (METHOD/APPROACH)}

Mathematics Modeling

Both authors A. NAMIR and A. EL KEBBAJ have equal contribution and credit.

\section{Council for Innovative Research}

Peer Review Research Publishing System

\section{Journal: INTERNATIONAL JOURNAL OF COMPUTERS \& TECHNOLOGY}

Vol 12, No.2

\section{editor@cirworld.com}




\section{INTRODUCTION}

In a context of globalized and very competitive market where the departments passed of the classic level (cost centered) at the strategic level (value centered), the decision-makers see their mission evolving towards the supply of services and the strategic partnership in the value creation.

For organizations (Company, State, Association) marked by an important transformation of their job(business) can be considered as a set of elements in dynamic interaction, organized according to a purpose or to an objective. Mathematically, she can be modeled by a dynamic system driven by its environment thanks to interactions which can be flows of information exciting the system from the outside (by the customers, the suppliers, the administrations) and also from the inside (by the various actors of the system).

Among the sub-systems which compose this system (figure 1), there are three important systems:

1. The system of piloting or decision where the activities are: think, decide and check(control) ;

2. The effective system, which the activities are: transform and produce ;

3. The information system which makes the link between the system of piloting and the effective system, which the activities are: generate information, memorize (store), broadcast and handle the information.

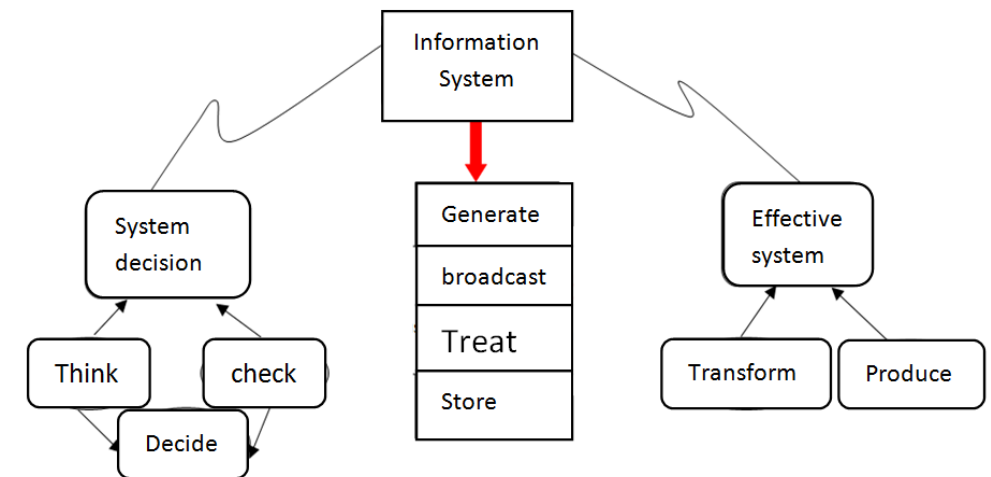

Figure 1

To reach the goal of the organization, the system must take into account its environment by adapting itself to the economic and social changes. It is a problem of regulation around a balance of the market.

Statistically, it was noticed by specialists of analysis that a person spends at least the tenth of his time to wait. In case of companies and in particular customer services, queues always give a negative impression of offered services quality and possibly a bad customer satisfaction. In that situation, companies will tend to find a compromise between the cost associated with the capacity of service and the cost of customers service delay.

The cost of service is the cost resulting from the preservation of certain level of service, for example the cost associated with the capacities of equipments, among the employees and among the servers. The costs of waiting are established by salaries paid to the employees who wait to make their work, the cost of the unusable equipments and naturally the cost associated with the loss of the impatient customers who goes to the competitors.

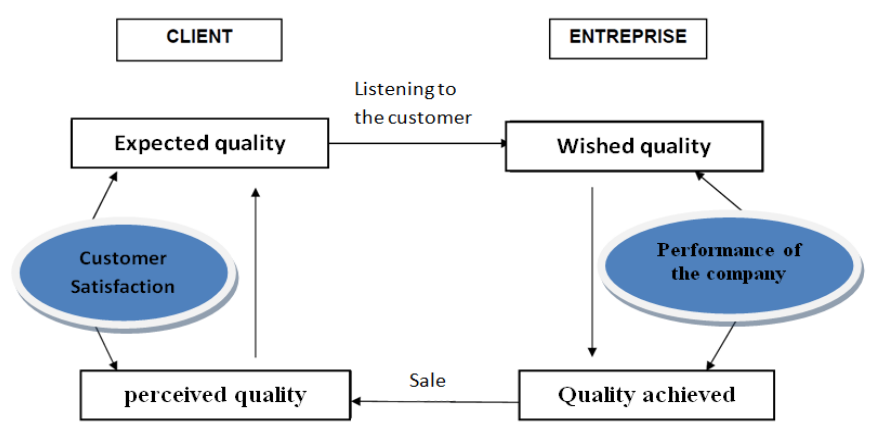

\section{Figure 2}

Generally, we see in the pending an added worthless activity, and a loss of time is associated with a bad quality of service. In the same way, idle employees or unusable equipments represent worthless activities added. To avoid these situations, companies should rather set up processes of continuous improvement the ultimate purpose of which is the elimination of any shape of wasting, in particular the pending. 
It is in this spirit where is situated this work, which consists in giving a contribution to the maximization of the processing in a communication network of company. That is proposing an approach which to eliminate any shape of wasting of time at the level of the processing inside an organization.

The introduction defined the frame of reflection in which is situated this work. it presented the problem approached as well as the contributions in the field of governance of companies. The series is constituted by 3 paragraphs:

In the 2nd paragraph, we model mathematically the problem posed by an integer linear programming. In the 3rd paragraph, we give a practical solution and a digital technology of the problem when we have rules of priority at the level of the services in the 4th paragraph; we illustrate the work by examples. The conclusion takes back the main lines of this study and our contribution. It also shows the diverse extra time and the possible perspectives of this work.

\section{MODELING OF THE PROBLEM}

We have a set of tasks (cases, requests, demands, expertise) handled by an organization and let us note:

- $\mathrm{L}=$ Lot of tasks to be periodically handled by the organization

- $\mathrm{N}=$ Number of tasks which the organization has to handle at the most during a period $(\operatorname{Car}(L) \leq N)$;

- $\mathrm{K}=$ Number of types of tasks to be periodically handled by the organization (Ki for $1 \leq \mathrm{i} \leq \mathrm{K}$ and $\mathrm{K} \leq \mathrm{N}$ ) ;

- $\mathrm{pi}=$ Minimal proportion of tasks of type Ki being necessarily and periodically in $\mathrm{L}$, with $1 \leq \mathrm{i} \leq \mathrm{K}$.

For every period $\mathrm{Pn}$ :

- $\mathrm{Ci}=$ Number of tasks of type Ki being to the organization for the period $\mathrm{Pn}$, with $1 \leq \mathrm{i} \leq \mathrm{K}$ (Ki capacity).

- $x i=$ Number of tasks of type Ki to deal by the organization for the period Pn, with $1 \leq \mathrm{i} \leq \mathrm{K}$ (flot Ki).

The problem to be solved consists, for period given $\mathrm{Pn}$, in maximizing cardinal of $\mathrm{L}$ which means maximizing the number of tasks to be handled by the organization, while respecting the constraints and then eliminate any shape of wasting of time at the level of the processing and of the service.

The problem can be mathematically modeled by the following model:

(S) \{

$$
\left\{\begin{array}{c}
\quad \operatorname{Max}\left(z=\sum_{i=1}^{K} x_{i}\right) \\
\text { S. C. } x_{i} \leq C_{i} \text { for } 1 \leq i \leq K \\
x_{i} \geq \operatorname{Min}\left\{C_{i}, p_{i} N\right\} \text { for } 1 \leq i \leq K \\
\sum_{i=1}^{K} x_{i} \leq N \\
x_{i} \in \mathbb{N}
\end{array}\right.
$$

Proof: we notice that the number of tasks which the organization can handle at the most during a period Pn is:

$$
\operatorname{Max}(Z)=\operatorname{Max}\left(\sum_{i=1}^{K} x_{i}\right)=\operatorname{Min}\left\{\sum_{i=1}^{K} C_{i}, N\right\}
$$

Two cases can appear:

1st case: $\mathrm{C}=\sum_{\mathrm{i}=1}^{\mathrm{i}=\mathrm{K}} \mathrm{C}_{\mathrm{i}} \leq \mathrm{N} \Rightarrow \operatorname{Max}(\mathrm{Z})=\sum_{\mathrm{i}=1}^{\mathrm{K}} \mathrm{C}_{\mathrm{i}}$

We put, for $1 \leq \mathrm{i} \leq \mathrm{K}, \mathrm{x}_{\mathrm{i}}=\mathrm{C}_{\mathrm{i}}$. Then $\left(\mathrm{x}_{1}, \mathrm{x}_{2}, \ldots, \mathrm{x}_{\mathrm{K}}\right)$ verify the constraints and we have:

$$
\mathrm{Z}=\sum_{\mathrm{i}=1}^{\mathrm{i}=\mathrm{K}} \mathrm{C}_{\mathrm{i}}=\operatorname{Max}(\mathrm{Z})
$$

Thus it is an optimal solution of problem (s).

Let us suppose that there is another solution $\left(x_{1}^{\prime}, x_{2}^{\prime}, \ldots, x_{K}^{\prime}\right) \neq\left(x_{1}, x_{2}, \ldots, x_{K}\right)$, then

$$
\exists \mathrm{j} \in\{1, \ldots, \mathrm{K}\} \text { such as } \mathrm{x}_{\mathrm{j}}^{\prime} \neq \mathrm{x}_{\mathrm{j}}=\mathrm{C}_{\mathrm{j}} \text {. }
$$

As $x_{j}^{\prime} \leq C_{j}$, we deduct that $x_{j}^{\prime}<C_{j}$ and as a consequence

$$
\mathrm{Z}=\sum_{\mathrm{i}=1}^{\mathrm{K}} \mathrm{x}_{1}^{\prime}=\sum_{\substack{\mathrm{i}=1 \\ \mathrm{i} \neq \mathrm{j}}}^{\mathrm{K}} \mathrm{x}_{\mathrm{i}}^{\prime}+\mathrm{x}_{\mathrm{j}}^{\prime}<\sum_{\substack{\mathrm{i}=1 \\ \mathrm{i} \neq \mathrm{j}}}^{\mathrm{K}} \mathrm{C}_{\mathrm{i}}+\mathrm{C}_{\mathrm{j}}=\sum_{\mathrm{i}=1}^{\mathrm{K}} \mathrm{C}_{\mathrm{i}}=\operatorname{Max}(\mathrm{Z})
$$

Contradiction. Then $\left(\mathrm{x}_{1}, \mathrm{x}_{2}, \ldots, \mathrm{x}_{\mathrm{K}}\right)$ is a unique solution of the problem (S). 
2nd case : $\mathrm{C}=\sum_{\mathrm{i}=1}^{\mathrm{i}=\mathrm{K}} \mathrm{C}_{\mathrm{i}}>N \Rightarrow \operatorname{Max}(\mathrm{Z})=\mathrm{N}$

Let $\mathrm{N}_{\mathrm{c}}=\left\{\mathrm{i} \in\{1, \ldots, \mathrm{K}\} / \mathrm{C}_{\mathrm{i}}>\mathrm{p}_{\mathrm{i}} \mathrm{N}\right\}$, we put

$$
x_{i}=\left\{\begin{aligned}
& C_{i} \text { if } i \notin N_{c} \\
& r_{i} \text { with } \quad r_{i} \in\left[p_{i} N, C_{i}\right] \text { and } \sum_{i \in N_{c}} r_{i}=N-\sum_{i \notin N_{c}} C_{i} \text { if } i \in N_{c}
\end{aligned}\right.
$$

$\operatorname{So}\left(\mathrm{x}_{1}, \mathrm{x}_{2}, \ldots, \mathrm{x}_{\mathrm{K}}\right)$ verify the constraints and

$$
\sum_{\mathrm{i}=1}^{\mathrm{i}=\mathrm{K}} \mathrm{x}_{\mathrm{i}}=\sum_{\mathrm{i} \in \mathrm{N}_{\mathrm{c}}} \mathrm{r}_{\mathrm{i}}+\sum_{\mathrm{i} \notin \mathrm{N}_{\mathrm{c}}} \mathrm{C}_{\mathrm{i}}=\mathrm{N}=\operatorname{Max}(\mathrm{Z})
$$

Then it is an optimal solution of the problem (S).

Remarque : if $\mathrm{C}=\sum_{\mathrm{i}=1}^{\mathrm{i}=\mathrm{K}} \mathrm{C}_{\mathrm{i}}>N$ so the solution is not generally unique.

\section{METHOD OF RESOLUTION}

In the majority of the systems of services, the rule of priority for the treatment of the tasks is the rule of first in first out (FIFO). However, in several situations, this rule is not applicable; because the cost or the consequences which result from it are not the same (for example the urgent tasks must be handled in the first one).

In these systems, we attribute to the tasks which appear one of the available rules of priority. By rule of priority, we understand the order of processing of the tasks. So, the tasks are classified by categories according to the rule of priority which is attributed to them.

The solution which we propose consists of choosing for $1 \leq \mathrm{i} \leq \mathrm{K}, \operatorname{Min}\left\{\mathrm{C}_{\mathrm{i}}, \mathrm{p}_{\mathrm{i}} \mathrm{N}\right\}$ tasks of type $\mathrm{Ki}$ and complete the batch tasks $L$, to deal by the organization, by what stays by respecting the order of priority.

\subsection{Proposal}

If we organize the types of tasks in ascending order by giving the priority to the first type $\mathrm{K} 1$ then the second type K2 then the third type K3 and so on, we have the optimal solution of (S) as follow:

$$
\text { (1) }\left\{\begin{array}{c}
\mathrm{x}_{1}=\operatorname{Min}\left\{\mathrm{C}_{1}, N-\sum_{\mathrm{i}=2}^{\mathrm{K}} \operatorname{Min}\left\{\mathrm{C}_{\mathrm{i}}, \mathrm{p}_{\mathrm{i}} \mathrm{N}\right\}\right\} \\
\left.\mathrm{x}_{\mathrm{i}}=\operatorname{Min}\left\{\mathrm{C}_{\mathrm{i}}, \mathrm{N}-\sum_{\mathrm{j}=1}^{\mathrm{i}-1} \mathrm{x}_{\mathrm{j}}-\sum_{\mathrm{j}=\mathrm{i}+1}^{\mathrm{K}} \operatorname{Min} \mathrm{C}_{\mathrm{j}}, \mathrm{p}_{\mathrm{j}} \mathrm{N}\right\}\right\} \text { for } 2 \leq \mathrm{i} \leq \mathrm{K} \\
\mathrm{x}_{\mathrm{K}}=\operatorname{Min}\left\{\mathrm{C}_{\mathrm{K}}, \mathrm{N}-\sum_{\mathrm{j}=1}^{\mathrm{K}-1} \mathrm{x}_{\mathrm{j}}\right\}
\end{array}\right.
$$

\subsection{Proof}

1st case: $\mathrm{C}=\sum_{\mathrm{i}=1}^{\mathrm{i}=\mathrm{K}} \mathrm{C}_{\mathrm{i}} \leq \mathrm{N}$

In this case $\mathrm{x}_{\mathrm{i}}=\mathrm{C}_{\mathrm{i}}$ for $1 \leq \mathrm{i} \leq \mathrm{K} \Rightarrow \operatorname{Max}(\mathrm{Z})=\sum_{\mathrm{i}=1}^{\mathrm{K}} \mathrm{C}_{\mathrm{i}}$

$\underline{2^{\text {nd }} \text { case }}: C=\sum_{i=1}^{i=K} C_{i}>N$

We reserve in the lot $\mathrm{L}$ tasks to be handled, $x_{i}=\operatorname{Min}\left\{C_{i}, p_{i} N\right\}$ tasks of every type $\mathrm{K}_{\mathrm{i}}$ for $1 \leq i \leq K$. It remains $N-\sum_{i=1}^{K} \operatorname{Min}\left\{C_{i}, p_{i} N\right\}$ tasks to choose.

- As $\mathrm{K}_{1}$ type is the first priority, we changed, if necessary, the value of $\mathrm{x}_{1}$ by :

$$
\mathrm{x}_{1}=\operatorname{Min}\left\{\mathrm{C}_{1}, \operatorname{Min}\left\{\mathrm{C}_{1}, \mathrm{p}_{1} \mathrm{~N}\right\}+\mathrm{N}-\sum_{\mathrm{i}=1}^{\mathrm{K}} \operatorname{Min}\left\{\mathrm{C}_{\mathrm{i}}, \mathrm{p}_{\mathrm{i}} \mathrm{N}\right\}\right\}
$$

It means that:

$$
\mathrm{x}_{1}=\operatorname{Min}\left\{\mathrm{C}_{1}, \mathrm{~N}-\sum_{\mathrm{i}=2}^{\mathrm{K}} \operatorname{Min}\left\{\mathrm{C}_{\mathrm{i}}, \mathrm{p}_{\mathrm{i}} \mathrm{N}\right\}\right\}
$$

$\mathrm{x}_{1}$ verify the constraint:

$$
\operatorname{Min}\left\{\mathrm{C}_{1}, \mathrm{p}_{1} \mathrm{~N}\right\} \leq \mathrm{x}_{1} \leq \mathrm{C}_{1}
$$

because 


$$
\operatorname{Min}\left\{\mathrm{C}_{1}, \mathrm{p}_{1} \mathrm{~N}\right\} \leq \mathrm{p}_{1} \mathrm{~N}=\mathrm{N}-\sum_{\mathrm{i}=2}^{\mathrm{K}} \mathrm{p}_{\mathrm{i}} \mathrm{N} \leq \mathrm{N}-\sum_{\mathrm{i}=2}^{\mathrm{K}} \operatorname{Min}\left\{\mathrm{C}_{\mathrm{i}}, \mathrm{p}_{\mathrm{i}} \mathrm{N}\right\}
$$

It remains $\mathrm{N}-\mathrm{x}_{1}-\sum_{\mathrm{i}=2}^{\mathrm{K}} \operatorname{Min}\left\{\mathrm{C}_{\mathrm{i}}, \mathrm{p}_{\mathrm{i}} \mathrm{N}\right\}$ tasks to choose.

- Then, as $K_{2}$ type is the 2 nd priority, we changed, if necessary, the value of $x_{2}$ by :

It means that:

$$
\mathrm{x}_{2}=\operatorname{Min}\left\{\mathrm{C}_{2}, \operatorname{Min}\left\{\mathrm{C}_{2}, \mathrm{p}_{2} \mathrm{~N}\right\}+\mathrm{N}-\mathrm{x}_{1}-\sum_{\mathrm{i}=2}^{\mathrm{K}} \operatorname{Min}\left\{\mathrm{C}_{\mathrm{i}}, \mathrm{p}_{\mathrm{i}} \mathrm{N}\right\}\right\}
$$

$\mathrm{x}_{2}$ verify the constraint:

$$
\mathrm{x}_{2}=\operatorname{Min}\left\{\mathrm{C}_{1}, \mathrm{~N}-\mathrm{x}_{1}-\sum_{\mathrm{i}=3}^{\mathrm{K}} \operatorname{Min}\left\{\mathrm{C}_{\mathrm{i}}, \mathrm{p}_{\mathrm{i}} \mathrm{N}\right\}\right\}
$$

because

$$
\mathrm{x}_{1} \leq \mathrm{N}-\sum_{\mathrm{i}=2}^{\mathrm{K}} \operatorname{Min}\left\{\mathrm{C}_{\mathrm{i}}, \mathrm{p}_{\mathrm{i}} \mathrm{N}\right\}=\mathrm{N}-\operatorname{Min}\left\{\mathrm{C}_{2}, \mathrm{p}_{2} \mathrm{~N}\right\}-\sum_{\mathrm{i}=3}^{\mathrm{K}} \operatorname{Min}\left\{\mathrm{C}_{\mathrm{i}}, \mathrm{p}_{\mathrm{i}} \mathrm{N}\right\}
$$

It means that

$$
\operatorname{Min}\left\{\mathrm{C}_{2}, \mathrm{p}_{2} \mathrm{~N}\right\} \leq \mathrm{N}-\mathrm{x}_{1}-\sum_{\mathrm{i}=3}^{\mathrm{K}} \operatorname{Min}\left\{\mathrm{C}_{\mathrm{i}}, \mathrm{p}_{\mathrm{i}} \mathrm{N}\right\}
$$

It remains

$$
\mathrm{N}-\mathrm{x}_{1}-\mathrm{x}_{2}-\sum_{\mathrm{i}=3}^{\mathrm{K}} \operatorname{Min}\left\{\mathrm{C}_{\mathrm{i}}, \mathrm{p}_{\mathrm{i}} \mathrm{N}\right\} \text { tasks to choose. }
$$

- And so on

Such as $\mathrm{C}=\sum_{\mathrm{i}=1}^{\mathrm{i}=\mathrm{K}} \mathrm{C}_{\mathrm{i}}>N$ and $\sum_{\mathrm{i}=1}^{\mathrm{i}=\mathrm{K}} \mathrm{P}_{\mathrm{i}} \mathrm{N}=\mathrm{N}$ then there is $\mathrm{K}^{\prime} \in\{1,2, \cdots, \mathrm{K}-1\}$ such as :

$$
\mathrm{N}-\sum_{\mathrm{i}=1}^{\mathrm{K}^{\prime}} \mathrm{x}_{\mathrm{i}}-\sum_{\mathrm{i}=\mathrm{K}^{\prime}+1}^{\mathrm{K}} \operatorname{Min}\left\{\mathrm{C}_{\mathrm{i}}, \mathrm{p}_{\mathrm{i}} \mathrm{N}\right\}=0
$$

It means that, from $\mathrm{K}^{\prime}+1, \mathrm{x}_{\mathrm{i}}$ can't be changed and consequently:

$$
\mathrm{x}_{\mathrm{i}}=\operatorname{Min}\left\{\mathrm{C}_{\mathrm{i}}, \mathrm{p}_{\mathrm{i}} \mathrm{N}\right\} \text { for } \mathrm{K}^{\prime}+1 \leq \mathrm{i} \leq \mathrm{K}
$$

Therefore

$$
\sum_{\mathrm{i}=1}^{\mathrm{K}} \mathrm{x}_{\mathrm{i}}=\mathrm{N} \Rightarrow \mathrm{Z}=\mathrm{N}
$$

This justifies that the solution given by equations(1) is an optimal solution of the system (S).

\section{EXAMPLES OF APPLICATION}

In these examples, we take $K=4, N=100$ and the priority is given to the first type $\mathrm{K} 1$ then the second type K2 and the third type $\mathrm{K} 3$ and so on.

\begin{tabular}{|c|c|c|c|c|c|c|c|c|c|c|c|c|c|}
\hline $\mathbf{p}_{\mathbf{1}}$ & $\mathbf{p}_{\mathbf{2}}$ & $\mathbf{p}_{\mathbf{3}}$ & $\mathbf{p}_{\mathbf{4}}$ & $\mathbf{c}_{\mathbf{1}}$ & $\mathbf{c}_{\mathbf{2}}$ & $\mathbf{c}_{\mathbf{3}}$ & $\mathbf{c}_{\mathbf{4}}$ & $\mathbf{x}_{\mathbf{1}}$ & $\mathbf{x}_{\mathbf{2}}$ & $\mathbf{x}_{\mathbf{3}}$ & $\mathbf{x}_{\mathbf{4}}$ & $\sum_{i=1}^{K} \boldsymbol{c}_{\boldsymbol{i}}$ & $\mathbf{Z}$ \\
\hline $100 \%$ & $0 \%$ & $0 \%$ & $0 \%$ & 0 & 0 & 20 & 80 & 0 & 0 & 20 & 80 & 100 & 100 \\
\hline $100 \%$ & $0 \%$ & $0 \%$ & $0 \%$ & 400 & 200 & 30 & 40 & 100 & 0 & 0 & 0 & 1300 & 100 \\
\hline $75 \%$ & $15 \%$ & $7 \%$ & $3 \%$ & 80 & 10 & 0 & 0 & 80 & 10 & 0 & 0 & 90 & 90 \\
\hline $90 \%$ & $7 \%$ & $3 \%$ & $0 \%$ & 0 & 0 & 0 & 50 & 0 & 0 & 0 & 50 & 50 & 50 \\
\hline $70 \%$ & $15 \%$ & $10 \%$ & $5 \%$ & 90 & 40 & 10 & 0 & 75 & 15 & 10 & 0 & 140 & 100 \\
\hline $65 \%$ & $15 \%$ & $10 \%$ & $10 \%$ & 70 & 30 & 10 & 0 & 70 & 20 & 10 & 0 & 110 & 100 \\
\hline
\end{tabular}

\section{CONCLUSION}

The realized work consists in designing a practical approach and a pragmatics implementation of tasks sequencing to maximize the processing in an organization for period given $P_{\mathrm{n}}$. Therefore, we proposed a method of mathematical modeling and a digital resolution described above.

This work opens the way to our sense towards diverse perspectives of research which are situated on two plans: a plan of deepening of the realized research and a plan of extension of the domain of research.

As for the deepening of the proposed work, it would be interesting at first of:

- Use the algorithm of GOMORY to solve numerically the programs ; 
- Suggest or designing practical tools of the implementation of the proposed approach ;

- Refine the approach by studying the roles of the actors and define them for every phase of the approach.

As for extension of the domain of the research, it would be interesting of:

- connect this approach with the governance of information systems;

- Pilot a decision-making system which consists in examining options and in comparing them to choose an action helping in the decision-making.

\section{REFERENCES}

[1] BUFFA, Elwood. Operations Management, 3e edition, New York, John Wiley \& Sons, 1972.

[2] FRITZSIMMONS, James A. et Mona J. FRITZSIMMONS. Service management : Operations, Strategy and Information Technology, 3e edition, New York, Irwin/McGraw-Hill, 2001.

[3] GRIFFIN, W. Queuing : Basic Theory and Applications, Columbus, Ohio, Grid Publishing, 1978.

[4] HILLIER, Frederick S., Mark S. HILLIER and Gerald J. LIEBERMAN. Introduction to Management Science : A Modeling and Case Studies Approach with Spreadsheets, New York, Irwin/McGraw-Hill, 2000.

[5] KARTZ, K. L., B. M. LARSON et R. C. LARSON. «Prescriptions for the Waiting-in-Line Blues : Entertain, Enlighten, and Engage », Sloan Management Review, vol. 32, n², hiver 1991, p. 44-53.

[6] STEVENSON, William J. Introduction to Management Science, 2e edition, Burr Ridge, IL., Richard D. Irwin, 1992.

[7] A. NAMIR and A. EL KEBBAJ. Modeling and maximizing the treatment in a network business communication. Day of Mathematics and Applications, Faculty of Sciences Ben M'Sik, Casablanca June 29, 2013

[8] A. EL KEBBAJ et A. NAMIR. Modeling customer's satisfaction. Day of Science Engineers, Faculty of Science Ben M'Sik, Casablanca july 29, 2013.

[9] A. NAMIR, E. LABRIJI, M. RACHIK and N. YOUSFI. Courses and Tutorials Operational Research - Linear Programming. Edition Hassan II University-Mohammedia, 2007.

[10] Sara Arezki, Zohair Adhiri and Abdelouahed Namir: Proposition of an IT governance plan. International Journal of Advanced Research in Computer Science and Software Engineering (IJARCSSE), Volume 2, issue 3 publishes on 25 March 2012.

[11] Z. Adhiri, S. Arezki, A. Namir : What is Application LifeCycle Management ?, International Journal of Research and Reviews in Applicable Mathematics and Computer- Science, ISSN: 2249 - 8931, December 2011

[12] Sara Arezki, Zohair Adhiri and Abdelouahed Namir : A GLOBAL APPROCH OF IT GOVERNANCE. International Journal of Mathematical Archive-2(9), sept. -2011, page : 1520-1522.

[13] Sara Arezki, Zohair Adhiri and Abdelouahed Namir : IT Governance: a Real or a Mythological Story. Int. J. Pure Appl. Sci. Technol., 2(2) (2011), pp. 22-25.

[14] S. ARIZKI : ITGovA : proposed a new approach to the governance of information systems. PhD in Computer Science, defended at the Faculty of Sciences of Ben M'Sik Casablanca 24/02/2013

[15] M. BADIA : Quality of Service and Artificial Intelligence: Application for Heterogeneous Networks for Optical Telecommunications. Thesis PhD in Mathematics \& Computer, Faculty of Science Ben M'Sik, Casablanca $17 / 07 / 2010$ 